\title{
NEWS/ANNOUNCEMENT
}

\section{The Eberhard F. Mammen Excellence in Thrombosis and Hemostasis Awards}

\begin{abstract}
As acknowledgment of Eberhard's contribution to the field of thrombosis and hemostasis in general, and to this journal in particular, the publisher, Thieme Medical Publishers, would like us to announce the creation of the Eberhard F. Mammen Excellence in Thrombosis and Hemostasis Awards. Thus, beginning in 2009, Seminars in Thrombosis and Hemostasis will begin a series of annual awards in recognition of excellence in the field of thrombosis and hemostasis. There will be two categories of awards:
\end{abstract}

- Most popular article awards: Awards for the most popular articles published in Seminars in Thrombosis and Hemostasis during the preceding 2 years. The awards comprise two major cash prizes of US $\$ 1000$, plus "open access" status for these articles thereafter. The awards will be determined by the editor in chief of
Seminars in Thrombosis and Hemostasis on the basis of download information provided by the publisher.

$>$ Young investigator awards: Best presentation or meeting abstract by a young investigator, as presented or delivered to an international meeting on a topic related to the field of thrombosis and hemostasis, and whose subject matter is determined to be in the spirit of Dr. Mammen. Up to six cash prizes of US\$1000 in any year will be awarded for one or more presentations at each of three or more international meetings per year. Each awardee will be expected to prepare a review or other related article on the topic of his or her presentation for publication in Seminars in Thrombosis and Hemostasis.

Further details about the awards will be provided to readers as these become available.
A Tribute to Eberhard F. Mammen, M.D. (1930-2008); Guest Editor, Emmanuel J. Favaloro, Ph.D., M.A.I.M.S.

Semin Thromb Hemost 2008;34:803-804. Copyright (C) 2008 by
Thieme Medical Publishers, Inc., 333 Seventh Avenue, New York, NY 10001, USA. Tel: +1(212) 584-4662.

DOI 10.1055/s-0029-1145264. ISSN 0094-6176. 